\title{
EVALUATION OF THE EFFECTIVENESS OF TREATMENT OF PATIENTS WITH TEMPOROMANDIBULAR JOINT DYSFUNCTION AFTER MANDIBULAR FRACTURES ACCORDING TO X-RAY EXAMINATION
}

D0I: 10.36740/WLek202109110

\author{
Olga L. Skrypa \\ BUKOVINIAN STATE MEDICAL UNIVERSITY, CHERNIVTSI, UKRAINE
}

\begin{abstract}
The aim: On the basis of radiological data to evaluate the effectiveness of our developed treatment complex of patients with temporomandibular joint dysfunction after mandibular fractures.

Materials and methods: To achieve this goal, 92 patients hospitalized in the department of surgical dentistry of the Chernivtsi Regional Clinical Hospital were examined for traumatic fractures of the mandible with functional disorders of the TMJ. 46 patients (main group) were treated according to the treatment method developed by us, and 46 patients (control group) were treated with the traditional method. Patients underwent orthopanthography and radiography of the temporomandibular joint according to Schuller. Statistical processing of research results was carried out using commonly used methods of variation statistics.

Results: After 12 months of studies in patients of the main group, unilateral narrowing of the joint space was determined in $6,52 \pm 1,83 \%$ of persons $p, p 10.05$. The number of persons with unilateral expansion of the joint space according to Rtg, in the main group decreased by 2,3 times relative to the data before treatment.

Conclusions: Timely treatment of musculoskeletal disorders with the help of pharmacological and physiotherapeutic methods proposed by us, allowed, to a large extent, to eliminate clinical, radiological and ultrasound symptoms of temporomandibular joint dysfunction in patients with post-traumatic lesions of mandibule. This was confirmed by the improvement of the data of the conducted functional researches.
\end{abstract}

KEY WORDS: X-ray examination, joint dysfunction, fracture of the mandible, TMJ

Wiad Lek. 2021;74(9 p.l):2082-2086

\section{INTRODUCTION}

Over the past 20-30 years, there has been increased attention of domestic and foreign scientists to diseases of the temporomandibular joints [1]. This is due to the fact that clinical signs of joint dysfunction, according to leading experts, can be found in $14-40 \%$ of the population, and the last 15 years, TMJ pathology ranks third after caries and periodontal disease among lesions of the dental system [2]. The problem of treatment and rehabilitation of patients with symptoms of musculoskeletal dysfunction of the TMJ is directly dependent on understanding the processes of pathomorphosis of their occurrence [3]. When choosing a method of treatment, doctors usually focus on local manifestations of dysfunction (limited or excessive mouth opening, pain and sound phenomena in the TMJ, etc.), which usually does not lead to the desired result during treatment. This is due to the fact that the features of functional and morphological disorders in individual components of the TMJ and adjacent anatomical formations are not taken into account $[4,5]$.

Prevention, diagnosis and treatment of damages of the maxillofacial area is one of the most urgent modern medical and social problems, the significance of which is determined by the constant increase in the frequency of maxillofacial injuries, which averages from 6,0 to $16,4 \%$ of all injuries of peacetime [6]. Prevalent these injuries in most cases in men, which is expressed in relation to women in the proportion of 7: $1-9: 1$, and their peak predominantly occurs in the second to fourth decades of life [7]. However, in recent years there has been a tendency to increase the number of victims is precisely at the age of 25 years. [8, 9]. Among injuries of the maxillofacial area fractures of the mandible are most common and occur in $67.3-87.1 \%$ of cases $[10,11]$. From 65,8 to $82 \%$ of the fractures of the mandible are localized within the dentition, and therefore are open [12].

The main attention in domestic and foreign literature was directed at the study of internal disorders in the TMJ, due to fractures of the of the processus frontalis [13]. The question of treatment of musculo-joint disorders caused by fractures of the mandible of other localizations, as a rule, was not addressed in a timely manner and, accordingly, not resolved $[14,15]$.

This explains the relevance of the study. Lack of purposeful early complex treatment of musculo-joint disorders caused by fractures of the mandible of different localization 
led to an inappropriate diagnosis and underestimation by all dental specialists (surgeons, therapists, orthopedists, orthodontists, etc.) [16].Therefore, today the problem is actual of comprehensive study of pathogenetic mechanisms of muscular articular dysfunction of the TMJ, improving the quality of its early diagnosis, as well as the implementation of differentiated targeted correction of the revealed violations and prevention of possible complications in patients with muscular and articular dysfunction of the TMJ with fractures mandibule of different localization.

\section{THE AIM}

On the basis of radiological data to evaluate the effectiveness of our developed treatment complex of patients with temporomandibular joint dysfunction after mandibular fractures.

\section{MATERIALS AND METHODS}

To achieve this goal, 92 patients hospitalized in the department of surgical dentistry of the Chernivtsi Regional Clinical Hospital were examined for traumatic fractures of the mandible with functional disorders of the TMJ. 46 patients (main group) were treated according to the treatment method developed by us (selection of joint splint "TMJ" (Australia), photodynamic therapy of the auricular-mandibular area of the affected joint was performed using the device "Bioptron - Compact III" (BIOPTRON AY, ZEPTER YROUP, Switzerland) with prior application of the gel "Bischofit Poltavskiy" and prescribed the drug "Teraflex Advance" ( 1 capsule 3 times per a day for 10 days)), and 46 patients (control group) were treated with the traditional method. Patients underwent orthopanthography and radiography of the temporomandibular joint according to Schuller. Statistical processing of research results was carried out using commonly used methods of variation statistics.

\section{RESULTS}

According to radiological studies, it was established (table I, II) that after 3-6 months of studies of significant radiological changes - narrowing / widening of the joint gap, displacement of the joint head forward / backward, the phenomena of osteoporosis, deforming arthrosis, in patients of the study group was not observed: against the background of a decrease in the number of persons with

Table I. Radiological disorders of the ratio of articular surfaces in patients with fractures of the mandible of the main group in different treatment periods.

\begin{tabular}{|c|c|c|c|c|}
\hline \multirow{2}{*}{\multicolumn{2}{|c|}{ Radiological disorders }} & \multicolumn{3}{|c|}{ Number of patients $\left(\frac{\text { abs.amount }}{M_{ \pm m, \%}}\right)$} \\
\hline & & $\begin{array}{l}\text { Before treatment } \\
\qquad n=46\end{array}$ & $\begin{array}{l}\text { 3-6 months after } \\
\text { treatment } n=46\end{array}$ & $\begin{array}{l}12 \text { months after } \\
\text { treatment } n=46\end{array}$ \\
\hline \multirow{2}{*}{$\begin{array}{l}\text { Narrowing of the joint } \\
\text { space }\end{array}$} & Unilateral & $\frac{11}{23,91 \pm 6,29}$ & $\frac{9}{19,57 \pm 5,84}$ & $\frac{3}{6,52 \pm 1,83}$ \\
\hline & Bilateral & $\frac{8}{17,39 \pm 5,59}$ & $\frac{6}{13,04 \pm 4,96}$ & $\frac{3}{6,52 \pm 1,83}$ \\
\hline \multirow{2}{*}{$\begin{array}{l}\text { Expansion of the joint } \\
\text { space }\end{array}$} & Bilateral & $\frac{21}{45,62 \pm 7,34}$ & $\frac{18}{39,13 \pm 7,19}$ & $\frac{9}{19,57 \pm 5,84}$ \\
\hline & Bilateral & $\frac{6}{13,04 \pm 4,96}$ & $\frac{4}{8,70 \pm 4,15}$ & $\frac{3}{6,52 \pm 1,83}$ \\
\hline \multirow{2}{*}{$\begin{array}{l}\text { Displacement of the } \\
\text { articular head to the front }\end{array}$} & Unilateral & $\frac{13}{28,26 \pm 6,63}$ & $\frac{10}{21,74 \pm 6,08}$ & $\frac{4}{8,70 \pm 4,15}$ \\
\hline & Bilateral & $\frac{6}{13,04 \pm 4,96}$ & $\frac{4}{8,70 \pm 4,15}$ & $\frac{2}{4,35 \pm 1,08}$ \\
\hline \multirow{2}{*}{$\begin{array}{c}\text { Displacement of the } \\
\text { articular head to the } \\
\text { backward }\end{array}$} & Unilateral & $\frac{17}{36,96 \pm 7,11}$ & $\frac{14}{30,43 \pm 6,78}$ & $\frac{7}{15,22 \pm 5,29}$ \\
\hline & Bilateral & $\frac{10}{21,74 \pm 6,08}$ & $\frac{8}{17,35 \pm 5,59}$ & $\frac{5}{10,87 \pm 4,58}$ \\
\hline \multirow{2}{*}{ Osteoporosis } & Unilateral & $\frac{11}{23,91 \pm 6,29}$ & $\frac{10}{21,74 \pm 6,08}$ & $\frac{6}{13,04 \pm 4,96}$ \\
\hline & Bilateral & $\frac{8}{17,39 \pm 5,59}$ & $\frac{8}{17,39 \pm 5,59}$ & $\frac{6}{13,04 \pm 4,96}$ \\
\hline Deforming arthrosis & Unilateral & $\frac{4}{8,70 \pm 4,15}$ & $\frac{4}{8,70 \pm 4,15}$ & $\frac{2}{4,35 \pm 1,08}$ \\
\hline
\end{tabular}

Bilateral

- $-p<0,05-$ a reliable difference in values regarding data before the treatment.

$*-p_{1}<0,05-$ a reliable difference in values regarding data 3-6 months after treatment 
Table II. Radiological disorders of the ratio of articular surfaces in patients with fractures of the mandible of the control group in different treatment periods

\begin{tabular}{|c|c|c|c|c|}
\hline \multicolumn{2}{|c|}{ Radiological disorders } & \multicolumn{3}{|c|}{ Number of patients $\left(\frac{a b s . a m o u n t}{M_{ \pm}, \%}\right)$} \\
\hline KadiologI & aers & \multirow{2}{*}{$\begin{array}{c}\begin{array}{c}\text { Before treatment } \\
\mathbf{n}=\mathbf{4 6}\end{array} \\
10\end{array}$} & $\begin{array}{l}\text { 3- } 6 \text { months after } \\
\text { treatment } n=46\end{array}$ & $\begin{array}{l}12 \text { months after } \\
\text { treatment } n=46\end{array}$ \\
\hline \multirow{4}{*}{$\begin{array}{c}\text { Narrowing of the joint } \\
\text { space }\end{array}$} & \multirow{2}{*}{ Unilateral } & & 8 & 7 \\
\hline & & $\overline{23,26 \pm 6,44}$ & $\overline{17,60 \pm 5,93}$ & $\overline{16,28 \pm 5,62}$ \\
\hline & \multirow{2}{*}{ Bilateral } & 9 & 7 & 6 \\
\hline & & $\overline{20,93 \pm 6,20}$ & $\overline{16,28 \pm 5,62}$ & $\overline{13,95 \pm 5,28}$ \\
\hline \multirow{4}{*}{$\begin{array}{c}\text { Expansion of the joint } \\
\text { space }\end{array}$} & \multirow{2}{*}{ Unilateral } & 19 & 17 & 16 \\
\hline & & $\overline{44,18 \pm 7,57}$ & $\overline{39,53 \pm 7,45}$ & $\overline{37,21 \pm 7,37}$ \\
\hline & \multirow{2}{*}{ Bilateral } & 5 & 3 & 3 \\
\hline & & $\overline{11,63 \pm 4,88}$ & $\overline{6,98 \pm 3,88}$ & $\overline{6,98 \pm 3,88}$ \\
\hline \multirow{4}{*}{$\begin{array}{l}\text { Displacement of the } \\
\text { articular head to the } \\
\text { front }\end{array}$} & \multirow{2}{*}{ Unilateral } & 12 & 10 & 9 \\
\hline & & $\overline{27,9 \pm 6,84}$ & $\overline{23,26 \pm 6,44}$ & $\overline{20,93 \pm 6,20}$ \\
\hline & \multirow{2}{*}{ Bilateral } & 7 & 5 & 5 \\
\hline & & $\overline{16,28 \pm 5,62}$ & $\overline{11,63 \pm 4,88}$ & $\overline{11,63 \pm 4,88}$ \\
\hline \multirow{4}{*}{$\begin{array}{c}\text { Displacement of the } \\
\text { articular head to the } \\
\text { backward }\end{array}$} & \multirow{2}{*}{ Unilateral } & 16 & 14 & 13 \\
\hline & & $\overline{37,21 \pm 7,27}$ & $\overline{32,56 \pm 7,14}$ & $\overline{30,23 \pm 7,00}$ \\
\hline & \multirow{2}{*}{ Bilateral } & 8 & 6 & 5 \\
\hline & & $\overline{18,60 \pm 5,93}$ & $\overline{13,95 \pm 5,28}$ & $\overline{11,63 \pm 4,88}$ \\
\hline \multirow{4}{*}{ Osteoporosis } & \multirow{2}{*}{ Unilateral } & 10 & 10 & 9 \\
\hline & & $\overline{23,26 \pm 6,44}$ & $\overline{23,26 \pm 6,44}$ & $\overline{20,93 \pm 6,20}$ \\
\hline & \multirow{2}{*}{ Bilateral } & 8 & 8 & 8 \\
\hline & & $\overline{18,60 \pm 5,93}$ & $\overline{18,60 \pm 5,93}$ & $\overline{18,60 \pm 5,93}$ \\
\hline \multirow{3}{*}{ Deforming arthrosis } & \multirow{2}{*}{ Unilateral } & 5 & 5 & 4 \\
\hline & & $\overline{11,63 \pm 4,88}$ & $\overline{11,63 \pm 4,88}$ & $\overline{9,30 \pm 4,42}$ \\
\hline & Bilateral & - & - & - \\
\hline
\end{tabular}

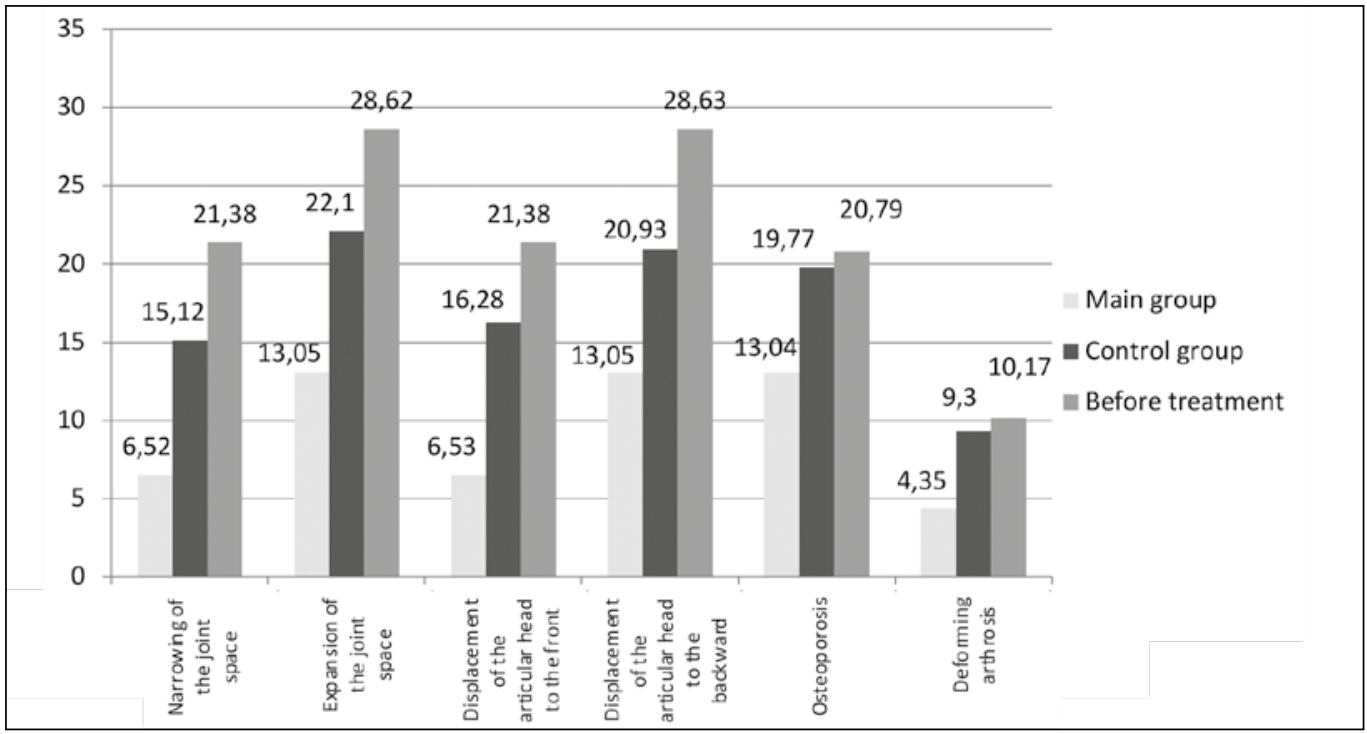

Fig. 1. Graphic representation of disorders of the ratio of articular surfaces in patients with fractures of the mandible 12 months after treatment.

the above symptoms, their percentage was equal to the data before treatment, $\mathrm{p}>0.05$.

After 12 months of studies in patients of the main group, unilateral narrowing of the joint space was determined in $6,52 \pm 1,83 \%$ of persons $p, p_{1}<0,05$, against $23,91 \pm 6,29 \%$ before treatment, and 16,28 $\pm 5,62 \%$ patients of the control group $\mathrm{p}, \mathrm{p}_{1}, \mathrm{p}_{2}>0,05$, against $23,26 \pm 6,44 \%$ of persons be- fore treatment. Bilateral narrowing of the joint space was diagnosed in 2,1 times fewer in the people of main group $(6.52 \pm 1.83 \%)$ than in the control group $-13.95 \pm 5.28 \%$ $\mathrm{p}, \mathrm{p}_{1}, \mathrm{p}_{2}>0.05$.

The number of persons with unilateral expansion of the joint space according to Rtg, in the main group decreased by 2,3 times relative to the data before treatment $(19,57 \pm$ 
$5,84 \%$ vs. $45,62 \pm 7,34 \%$ p, $\left.p_{1}<0.05\right)$. At the same time, in the control group, the decrease in the number of persons with this Rtg parameter was insignificant $-37,21 \pm 7,37 \%$ of persons against $44,18 \pm 7,57 \%$ before treatment, $p, p_{1}, p_{2}>$ 0,05 . Twelve months after treatment, bilateral expansion of the joint space occurred in the same number of individuals in the study groups: $6,52 \pm 1,83 \%$ in the main and $6,98 \pm$ $3,88 \%$ treated in the control group $\mathrm{p}, \mathrm{p}_{1}, \mathrm{p}_{2}>0.05$.

At this time of observation according to Rtg data, the number of persons with displacement of the articular head to the front decreased: with unilateral displacements 3.2 times in the main group, $\mathrm{p}<0,05, \mathrm{p}_{1}>0,05$, and 1,3 times in the control group $\mathrm{p}, \mathrm{p}_{1}, \mathrm{p}_{2}>0,05$; at bilateral displacements: 2,9 times in the main group, $p, p_{1}>0,05$, and 1,4 times in the control group, $p, p_{1}, p_{2}>0,05$. In the main group there was a decrease in the number of patients with displacement of the articular head back, in relation to the data before treatment: with unilateral displacement of 2.4 times, $p<0,05$, and with bilateral $-2,0$ times, $p>$ 0,05 . In the control group, the decrease in the number of patients according to this Rtg - symptom was relatively moderate, and was 1,2 times - with unilateral and 1,6 times - with bilateral displacements below the reference values, $\mathrm{p}>0,05$.

After one year of observation, the phenomenon of unilateral and bilateral osteoporosis in the treated main group was observed 1,8 and 1,3 times less often than before treatment, $p, p_{1}>0,05$, respectively. In the control group, $20,93 \pm 6,20 \%$ of patients showed unilateral osteoporosis against $23,26 \pm 6,44 \%$ of subjects before treatment $p, p_{1}>$ 0,05 . At the same time, Rtg - improvements in bilateral osteoporosis in patients of this group were not objectified.

After 12 months of follow-up, deforming unilateral osteoarthritis was determined in $4,35 \pm 1,08 \%$ after the treatment, against $8,70 \pm 4,15 \%$ before treatment in the main group $p, p_{1}>0,05$; and in $9,30 \pm 4,42 \%$ after the treatment against $11,63 \pm 4,88 \%$ before treatment in the control group $\mathrm{p}, \mathrm{p}_{1}, \mathrm{p}_{2}>0,05$ (Fig. 1).

\section{DISCUSSION}

The main task of treatment of patients with traumatic fractures of the mandible is to create conditions for the fusion of fragments in the correct position in the shortest possible time [17]. Treatment should ensure complete restoration of mandibular function. To solve these problems it is necessary to reposition and fix the jaw fragments for the period of their consolidation, to create favorable conditions for reparative regeneration of bone tissue, prevention of purulent-inflammatory complications, to ensure early recovery of functional load $[18,19]$.

According to various literature sources, the number of complications after osteosynthesis reaches up to $6 \%[20,21]$. At the same time there is an opinion that at considerable shifts of fragments it is necessary to use osteosynthesis in combination with additional intermaxillary fixation.

Orthopedic methods, the most common in clinical practice and, according to various authors, account for about
$87 \%$ of the total number of treatments currently performed in our country $[22,23,24]$. These methods involve fixing and immobilizing the fragments of the mandible with intraoral splints, mainly wire dental with intermaxillary traction. In particular, professional sources also emphasize the need to begin treatment of uncomplicated mandibular fractures using the least invasive methods. Thus, a single-jaw splint-bracket is using for partial fractures of the cell process or linear fractures of the mandible. A justified alternative may be the use of dental adhesive splinting with a bracket system. In some cases, actual is ligature of the teeth or the use of loops in fractures of the mandible with a slight displacement. Today, the most commonly used modified dental splints with a spacer bend and a corrective element at the level of the fracture slit and hook loops on each of the fragments for intermaxillary rubber traction [25].

Under conditions of functional load, the transformation of callus into mature bone takes from 14 to 21 days, and in its absence, the formation of mature cancellous bone tissue is observing 30 or more days after injury. Thus, the duration of fracture treatment is reducing due to a combination of periods of consolidation and active rehabilitation [26].

Many works have been devoted to the issue of accelerating the regeneration of mandibular tissues and preventing complications after fractures. Currently, this problem is solving by developing reliable fixations of fragments, stimulation of reparative osteogenesis, physical exposure (laser radiation, direct electric current, magnetic field, etc.) [27]. Many authors, without diminishing the importance of early and reliable fixation of fragments, rational tactics for the tooth in the fracture line, focused on the state of general and local immunity - factors that largely determine the likelihood of infectious and inflammatory complications.

Taking this circumstance into account, schemes of complex prevention of complications of mandibular fractures have been proposed in the literature. These include the use of specific and nonspecific immunostimulants.

Thus, in the pathogenetically - directed, our proposed treatment of chronic musculoskeletal disorders of the TMJ on the background of fractures of the mandible, we were able to obtain positive results according to radiological studies. According to the parameters obtained by us, this trend was observed for more than 6 months. When using traditional treatment methods in patients with this combined dental pathology, 1 year after treatment, a probable increase in the number of patients with normal occlusion and the state of the TMJ, relative to baseline values, was investigated. At the same time, the positive clinical dynamics was weakly confirmed by radiological examination.

\section{CONCLUSIONS}

Timely treatment of musculoskeletal disorders with the help of pharmacological and physiotherapeutic methods proposed by us, allowed, to a large extent, to eliminate clinical, radiological and ultrasound symptoms of temporomandibu- 
lar joint dysfunction in patients with post-traumatic lesions of mandibule. This was confirmed by the improvement of the data of the conducted functional researches.

\section{REFERENCES}

1. Murray J. M. Mandible fractures and dental trauma. Emerg. Med. Clin. North. Am. 2013; 31( 2): 553-573.

2. Skrypa 0.L., Bandrivsky Y. L. Determining the frequency of functional disorders of the tmj in patients with mandible fractures depending on the location. Wiad. Lek. 2020:2:245 - 249.

3. Boffano P., Roccia F., Zavatteroet E. et. al. European Maxillofacial Trauma (EURMAT) project: A multicentre and prospective study . J. Craniomaxillofac. Surg. 2015; 43(1): 62-70.

4. Cabalag M., Wasiak J., Andrew N. et.al. Epidemiology and management of maxillofacial fractures in an Australian trauma centre. J. Plast Reconstr Aesthet Surg. 2014; 67(2): 183-189.

5. Gutta R., Tracy K., Johnson C. et. al. Outcomes of mandible fracture treatment at an academic tertiary hospital: a 5-year analysis. J. Oral. Maxillofac Surg. 2014; 72(3): 550-558.

6. Hilgenberg-Sydney P.B., Bonotto D.V.,Stechman-Neto J. et al. Diagnostic validity of $\mathrm{CT}$ to assess degenerative temporomandibular joint disease: a systematic review. Dentomaxillofac Radiol. 2018;47(5):20170389. doi:10.1259/dmfr.20170389.

7. Hammer M.R., Kanaan Y. Imaging of the Pediatric Temporomandibular Joint. Oral Maxillofac Surg Clin North Am. 2018;30(1):25-34. doi:10.1016/j.coms.2017.08.008.

8. Sperry M.M., Kartha S., Winkelstein B.A., Granquist E.J. Experimental Methods to Inform Diagnostic Approaches for Painful TMJ Osteoarthritis. J Dent Res. 2019;98(4):388-397. doi:10.1177/0022034519828731.

9. Wilkes C.H. International Derangement of the Temporomandibular Joint. J. Otolaringol. Head Neck Surg. 1989; 115: 469-477.

10. Petrosov Yu.A., Kalpakyants 0.Yu., Seferyan N.Yu. Diseases of the temporomandibular joint. Krasnodar: Soviet Kuban, 2009, p. 352.

11. LeResche L. Epidemiology of temporomandibular disorders: implications for the investigation of etiologic factors. Crit. Rev. Oral. Biol. Med. 2014; 8:291-305

12. Smahlyuk L.V., Trofymenko M.V. The structure of symptoms of temporomandibular joint dysfunction depending on the morphofunctional status of the dentofacial area. Dentistry Journal. 20015; 2(47):75-77.

13. Schiffman E., Ohrbach R. Executive summary of the Diagnostic Criteria for Temporomandibular Disorders for clinical and research applications. JAm Dent Assoc. 2016;147(6):438-445. doi:10.1016/j.adaj.2016.01.007

14. Manfredini D., Segù M., Arveda N. et al. Temporomandibular Joint Disorders in Patients With Different Facial Morphology. A Systematic Review of the Literature. J Oral Maxillofac Surg. 2016;74(1):29-46. doi:10.1016/j.joms.2015.07.006.

15. Larheim T.A., Hol C., Ottersen M.K. et al. The Role of Imaging in the Diagnosis of Temporomandibular Joint Pathology. Oral Maxillofac Surg Clin North Am. 2018;30(3):239-249. doi:10.1016/j.coms.2018.04.001.

16. Toure G. Arterial Vascularization of the Mandibular Condyle and Fractures of the Condyle. Plast Reconstr Surg. 2018;141(5):718e-725e. doi:10.1097/PRS.0000000000004295.

17. Abdel-Galil K., Loukota R. Fractures of the mandibular condyle: evidence base and current concepts of management. Br J Oral Maxillofac Surg. 2010;48(7):520-526. doi:10.1016/j.bjoms.2009.10.010.
18. Bandrivsky Y., Bandrivska 0., Gnid R. et al. Indicators of markers of bone metabolism in patients with generalized periodontitis depending on blood group. Arch Balk Med Union. 2019; 54(1):72-77. doi. org/10.31688/ABMU.2019.54.1.10.

19. García-Guerrero I., Ramírez J.M., Gómez de Diego R. et al. Complications in the treatment of mandibular condylar fractures: Surgical versus conservative treatment. Ann Anat. 2018;216:60-68. doi:10.1016/j. aanat.2017.10.007.

20. Cranford J., Kadakia S., Sawhney R., DucicY. Contemporary Issues in the Open Management of Subcondylar Fractures of the Mandible. Facial Plast Surg. 2016;32(4):424-430. doi:10.1055/s-0036-1584554.

21. Hackenberg B., Lee C., Caterson E.J. Management of subcondylar mandible fractures in the adult patient. J Craniofac Surg. 2014;25(1):166171. doi:10.1097/SCS.0000000000000498.

22. Shiju M., RastogiS., Gupta P. et al. Fractures of the mandibular condyle-Open versus closed--A treatment dilemma. J Craniomaxillofac Surg. 2015;43(4):448-451. doi:10.1016/j.jcms.2015.01.012.

23. Nam S.M., Kim Y.B., Cha H.G. et al. Transoral Open Reduction for Subcondylar Fractures of the Mandible Using an Angulated Screwdriver System. Ann Plast Surg. 2015;75(3):295-301. doi:10.1097/ SAP.0000000000000011.

24. Hirjak D., Machon V., Beno M. et al. Surgical treatment of condylar head fractures, the way to minimize the postraumatic TMJ ankylosis. Bratisl Lek Listy. 2017;118(1):17-22. doi:10.4149/BLL_2017_004.

25. Belli E., Liberatore G., Elidon M. et al. Surgical evolution in the treatment of mandibular condyle fractures [published correction appears in BMC Surg. 2015;15:70. Elidon, Mici [corrected to Mici, Elidon]]. BMC Surg. 2015;15:16.

26. Shakya S., Zhang X., Liu L. Key points in surgical management of mandibular condylar fractures. Chin J Traumatol. 2020;23(2):63-70. doi:10.1016/j.cjtee.2019.08.006.

27. Tabrizi R., Bahramnejad E., Mohaghegh M., Alipour S. Is the frequency of temporomandibular dysfunction different in various mandibular fractures?. J Oral Maxillofac Surg. 2014;72(4):755-761. doi:10.1016/j. joms.2013.10.018.

\section{ORCID and contributionship:}

Olga L. Skrypa: 0000-0003-2823-1719 A-F

\section{Conflict of interest:}

The Author declare no conflict of interest.

\section{CORRESPONDING AUTHOR}

\section{Olga L. Skrypa}

Bukovinian State Medical University

6/74 Kopernika st., 58000 Chernivtsi, Ukraine

tel: +380503737557

e-mail: identist83@gmail.com

Received: 17.09 .2020

Accepted: 02.06 .2021

A - Work concept and design, B - Data collection and analysis, C - Responsibility for statistical analysis,

D-Writing the article, $\mathbf{E}$-Critical review, $\mathbf{F}$ - Final approval of the article 